\title{
Attendance Trend of Specialist Oral Healthcare in Ministry of Malaysia, Malaysia during Pandemic COVID-19
}

\author{
Rapeah Mohd Yassin ${ }^{1}$, Harathi a/p Dorairaja ${ }^{1}$, Fauziah Ahmad', Noormi Othman ${ }^{1}$ \\ ${ }^{1}$ Oral Health Programme, Ministry of Health, Malaysia
}

Objectives: Specialist Oral Healthcare, Ministry of Health Malaysia include Oral and Maxillofacial Surgery, Paediatric Dentistry, Oral Pathology and Oral Medicine, Special Care Dentistry, Forensic Odontology, Orthodontic, Periodontic and Restorative Dentistry. Movement Control Order was executed by the federal government of Malaysia in response to the COVID-19 pandemic led to limited dental procedures. This study aimed to determine the impact of pandemic COVID-19 on the attendance of Specialist Oral Healthcare.

Methods: Total attendance of all patients from each dental specialty was traced from secondary data available at Health Information Management System in a monthly basis from January 2019 to December 2020 January to May 2021. Dental record for each specialty was named as PG208, PG209, PG 212, PG 213, PG 215, PG216, PG SND 201 and PG FOD 201 for Orthodontic, Oral and Maxillofacial Surgery, Periodontic, Paediatric Dentistry, Oral Pathology and Oral Medicine, Restorative Dentistry, Special Care Dentistry and Forensic Odontology specialty respectively. Descriptive statistics was used to analyse the trends of patient's attendance on a monthly basis during MCO for each specialty accordingly.

Results: Total attendance of Specialist Oral Healthcare decreased by $28.8 \%$ in 2020 as compared to 2019 but recovered with $22.5 \%$ increase in 2021 (January to May) as compared to 2020 (January to May). By specialty, attendance decreased 16.6\%, $28.5 \%, 19.1 \%, 33.7 \%, 38.7 \%, 42.8 \%$, and 37.0\% for Oral and Maxillofacial Surgery, Paediatric Dentistry, Oral Pathology and Oral Medicine, Special Care Dentistry, Orthodontic, Periodontic and Restorative Dentistry respectively. Total attendance of Forensic Dentistry increased $8.1 \%$ in 2020 versus 2019.

Conclusions: Attendance of Specialist Oral Healthcare in Ministry of Health Malaysia decreased by a third in 2020 during MCO following pandemic COVID-19 compared to 2019. However, it recovered with the implementation of new norms among personnel, availability of additional supportive equipment and on-line appointment system.

Keywords: pandemic COVID-19, Movement Control Order, Specialist Oral Healthcare

Copyright (C) 2021. Korean Academy of Preventive Dentistry. All rights reserved.

This is an Open Access article distributed under the terms of the Creative Commons Attribution Non-Commercial License (http://creativecommons.org/licenses/ by-nc/4.0) which permits unrestricted non-commercial use, distribution, and reproduction in any medium, provided the original work is properly cited. 